\title{
Impact of Sizing on the Temperature of Automotive Lighting Products
}

\author{
Mustafa Emre Bayraktar, Mehmet Aktaş \\ Magneti Marelli Mako AŞ \\ Nilufer, Bursa, Turkey \\ mustafaemre.bayraktar@magnetimarelli.com; mehmet.aktas@magnetimarelli.com
}

\begin{abstract}
In this study effect of geometrical size on temperature in automotive lighting units is experimentally and numerically investigated. In the experimental phase a product, which includes a P21W type bulb, with clear polycarbonate (PC) material in rectangular section is used. 5 thermocouples are used for temperature measurements. Numerical investigation is conducted with the same geometry and material properties by ANSYS CFX 12.1. In this investigation flow is assumed to be steady and laminar and 3 dimensional (3D) Navier-Stokes equations are used for calculation. It is observed that numerical results are consistent with experimental measurement in terms of temperatures. In the numerical studies where the effect of geometrical size on temperature is investigated distance between filament - housing (z1), distance between filament - housing side surface (y) and distance between filament - lens (x) are examined. It is observed that the greatest temperature decline is observed when $\mathrm{z} 1$ is increased. $\mathrm{y}$ is the least effective one on temperature among investigated parameters. The greatest temperature drop for lens is obtained by change in $\mathrm{x}$.
\end{abstract}

Keywords: Automotive lighting, heat transfer, plastics, computational fluid dynamics (CFD)

\section{Introduction}

Plastic components used in automotive lighting products may encounter deformations due to the heat that are generated by bulbs. Although these deformations are mostly aesthetical problems, sometimes they damage the reflector surfaces and can change the reflection property of the product. It is quite important to take actions against this issue by considering temperature effects during the development phase of the product to avoid safety problems. For this reason it is a common practice to make calculations during development to estimate temperatures on the product by using computational fluid dynamics (CFD) method.

There are several studies in the literature that use CFD to estimate temperature on the automotive lighting products [1] [2]. Physical experiment may also be employed to figure out the temperature distribution and fluid flow inside the headlamp [3].

For precisely managing the design of the product it is important to investigate the parameters that affect the temperature. Type of the bulb can be considered as one of the parameters. Bulbs working on high power will produce high amount of heat and the correct components must be chosen for this design to resist this heat. Another parameter might be the investigation of the necessity of using metal shields that can be used inside the lighting product to block the heat from reaching the plastic components. The disadvantages of introducing a shield are the increased cost and weight of the product. Another design related parameter is the investigation of the distances between the components and the lighting source, which is one of the most cost friendly approaches in thermal management of automotive lighting design. In this study influence of distance between light source and the housing and the lens is investigated with the help of CFD. A physical experiment was also conducted to validate the results.

\section{Physical Experiment}

In the experimental study a box which is made of semi-transparent PC is used (Fig. 1). Inside the box a P21W bulb is placed. For ensuring the constant ambient temperature and minimizing the air movement around the box the experiment is done inside a large enclosed cavity i.e. climatic chamber with the environment temperature of $25^{\circ} \mathrm{C}$. 

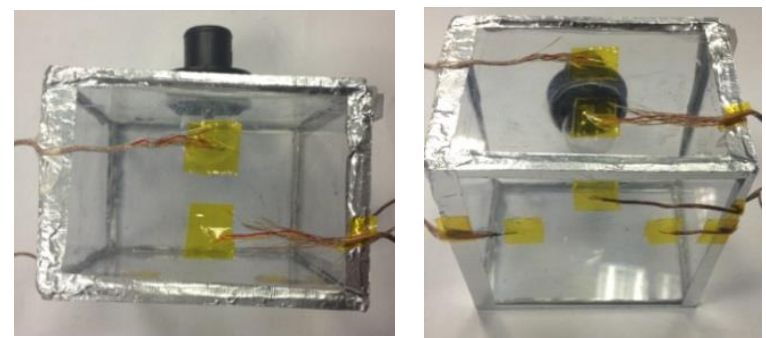

Fig. 1: Box used in experiment.

For temperature measurement 5 thermocouples are used, 3 of them placed in front face of the box and the rest 2 on top of the box. Positions of the thermocouples T1, T2, T3, T4, T5 and the dimensions of the box can be seen in Fig. 2. The thickness of the box plates is $3.3 \mathrm{~mm}$ and the hole for bulb placement is $27.5 \mathrm{~mm}$ in diameter.

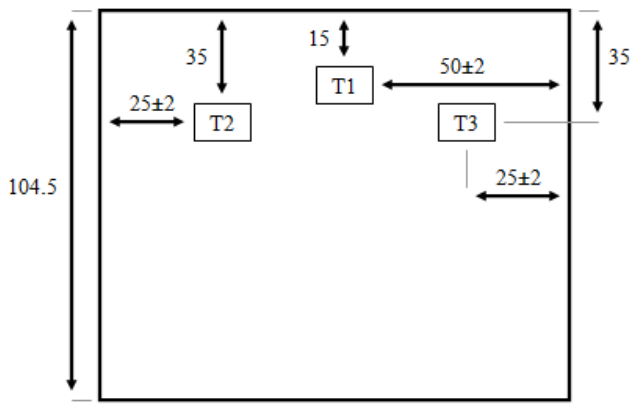

(a)

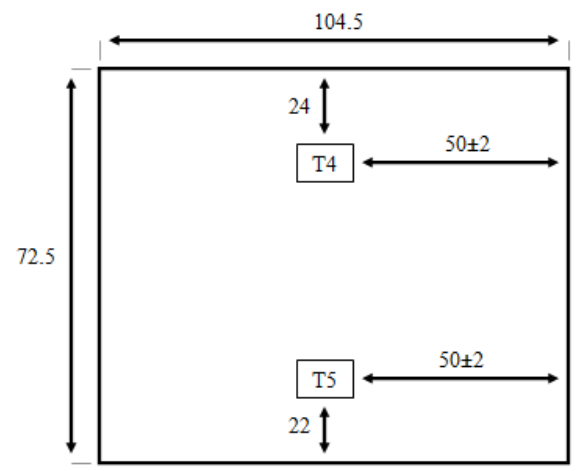

(b)

Fig. 2: Box dimensions and thermocouple positions.

For switching on the bulb $13.5 \mathrm{~V}$ tension is applied. The measured current is $1.82 \mathrm{~A}$ and the consumed power is $24.57 \mathrm{~W}$. It has been observed that the temperatures became steady after almost 30min of operation. (Fig 3.) represents the measured temperature values with thermocouples.

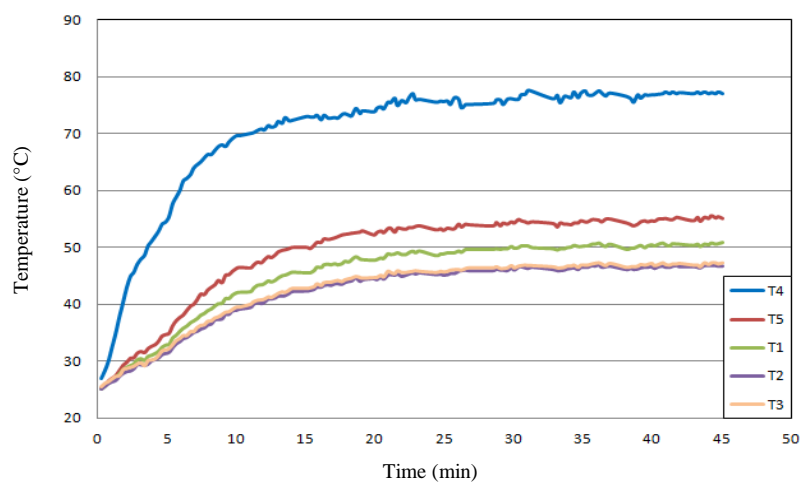

Fig. 3: Change of measured temperature with time.

The highest temperature is measured on $\mathrm{T} 4$ thermocouple which is on top of the box as $77.5^{\circ} \mathrm{C}$. $\mathrm{T} 5$, which is also on top surface, is measured $56^{\circ} \mathrm{C}$. Front surface temperatures measured with $\mathrm{T} 1, \mathrm{~T} 2, \mathrm{~T} 3$ are $51^{\circ} \mathrm{C}, 47^{\circ} \mathrm{C}$ and $47.5^{\circ} \mathrm{C}$ respectively. 


\section{Numerical Study}

The first numerical work is done to validate the results obtained from experimental study. Mesh structure consists of approximately 1.5 million tetrahedral elements. 3D geometry includes semi-transparent box, bulb, bulb socket and a sphere to represent the boundary of the air cavity that surrounds the box. The radius of the sphere is chosen to be $\mathrm{L}=106 \mathrm{~mm}$ which more than triples the horizontal length of the box (Fig. 4).

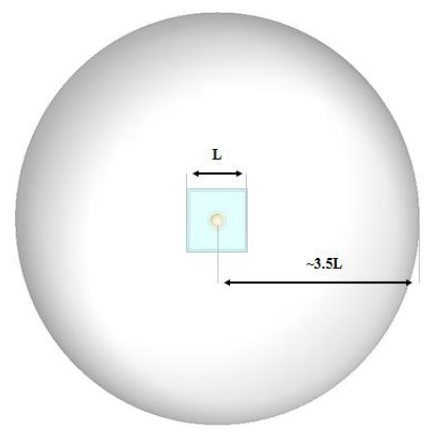

Fig. 4: Computational domain.

\subsection{Validation Case}

\section{Boundary Conditions and Assumptions}

In the numerical analysis the fluid flow is assumed to be laminar and in steady state. For the calculation of flow field and heat transfer 3D continuity, momentum and energy equations are solved with the help of ANSYS CFX 12.1, the commercial CFD software. The related equations can be written in cartesian coordinate system for incompressible and steady state flow by applying Bossinesq approach where the $\mathrm{z}$ is the gravity axis as shown in Eqs. (1) - (5) below.

$$
\begin{gathered}
\frac{\partial \mathrm{u}}{\partial \mathrm{x}}+\frac{\partial \mathrm{v}}{\partial \mathrm{y}}+\frac{\partial \mathrm{w}}{\partial \mathrm{z}}=0 \\
u \frac{\partial u}{\partial x}+v \frac{\partial u}{\partial y}+w \frac{\partial u}{\partial z}=-\frac{1}{\rho} \frac{\partial p}{\partial x}+v\left(\frac{\partial^{2} u}{\partial x^{2}}+\frac{\partial^{2} u}{\partial y^{2}}+\frac{\partial^{2} u}{\partial z^{2}}\right) \\
u \frac{\partial v}{\partial x}+v \frac{\partial v}{\partial y}+w \frac{\partial v}{\partial z}=-\frac{1}{\rho} \frac{\partial p}{\partial y}+v\left(\frac{\partial^{2} v}{\partial x^{2}}+\frac{\partial^{2} v}{\partial y^{2}}+\frac{\partial^{2} v}{\partial z^{2}}\right) \\
u \frac{\partial w}{\partial x}+v \frac{\partial w}{\partial y}+w \frac{\partial w}{\partial z}=-\frac{1}{\rho} \frac{\partial p}{\partial z}+v\left(\frac{\partial^{2} w}{\partial x^{2}}+\frac{\partial^{2} w}{\partial y^{2}}+\frac{\partial^{2} w}{\partial z^{2}}\right)+g \beta\left(T-T_{\infty}\right) \\
u \frac{\partial T}{\partial x}+v \frac{\partial T}{\partial y}+w \frac{\partial T}{\partial z}=\alpha\left(\frac{\partial^{2} T}{\partial x^{2}}+\frac{\partial^{2} T}{\partial y^{2}}+\frac{\partial^{2} T}{\partial z^{2}}\right)
\end{gathered}
$$

$\alpha$ in Eq. (5) represents the thermal diffusivity, $v$ in Eqs. (2) - (4) is the kinematic viscosity and $\beta$ in Eq. (4) is the thermal expansion coefficient. $T$ in Eqs. (4) - (5) denotes the temperature. Gravitational force is effective in the $\mathrm{z}$ direction; therefore the term consists of gravitational constant $g$ is used in Eq. (4). The bulb and box surfaces were assigned as wall and no slip wall boundary condition was applied for these surfaces. On all the surfaces of the bulb and of the box the velocity is set to $0 \mathrm{~m} / \mathrm{s}$. Boundary conditions can be listed as below.

Velocity; for all the walls, $\mathrm{u}=\mathrm{v}=\mathrm{w}=0 \mathrm{~m} / \mathrm{s}$

Pressure; ambient sphere surface, $\mathrm{p}=1 \mathrm{~atm}$

Temperature; ambient sphere surface, $\mathrm{T}_{\infty}=25^{\circ} \mathrm{C}$ 
In the study, the PC box and bulb glass were defined as semi-transparent materials, the bulb socket and filament however were assigned as opaque. For calculation of radiative heat transfer Monte-Carlo model was used considering its numerical stability and accuracy in results which was shown in similar studies previously [4].

Tungsten material was chosen for the filament inside the bulb. Considering power loss from bulb is $\mathrm{P}=24.57 \mathrm{~W}$ and $V_{f}$ is the volume of filament, $P / V_{f}$ is defined as volumetric heat source of filament.

\section{Results and Comparison}

It can be seen from the numerical study and experiment comparison that maximum temperature difference is in $\mathrm{T} 5$ thermocouple and the deviation is $8.25 \%$ and the minimum difference is in T4 which corresponds $1.15 \%$ of deviation. Temperature difference for $\mathrm{T} 1, \mathrm{~T} 2$ and $\mathrm{T} 3$ are $2.25 \%, \% 1.6 \%$ and $3.28 \%$ respectively. Calculated and measured temperatures can be seen in below (Fig. 5).

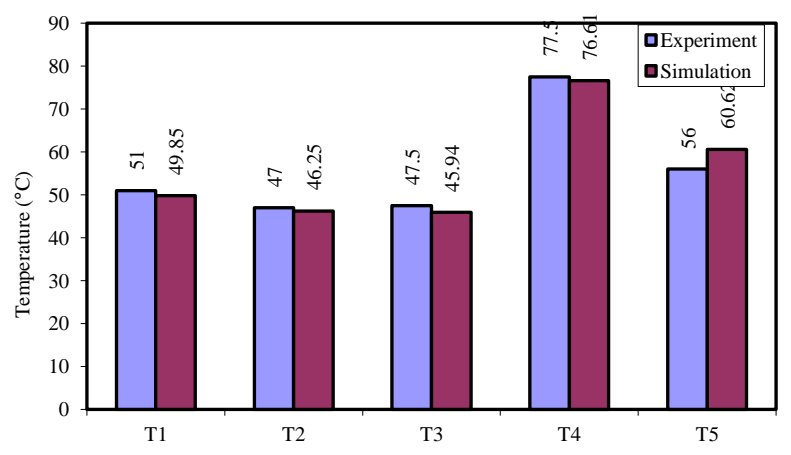

Fig. 5: Temperature comparison.

Calculated temperature distribution for box's top and front outer surfaces is given in below (Fig.6). "+" sign denotes the measurement locations.

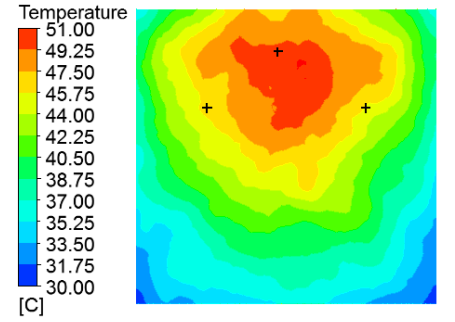

a)

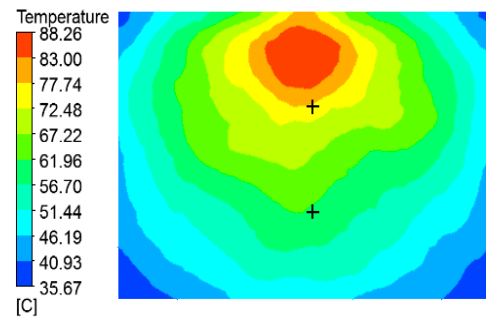

b)

Fig. 6: Calculated temperature distribution on a) front surface and b) top surface of the box.

Maximum temperature over the top surface of the box is calculated as $88^{\circ} \mathrm{C}$. It is seen that its location lies just behind the T4 thermocouple (Fig. 6). Velocity distribution is given in (Fig. 7) and maximum velocity is calculated close to $0.3 \mathrm{~m} / \mathrm{s}$ on top of the bulb. Rise of the air as it is seen in (Fig. 7) is thought to be caused by temperature difference which results in local density differences inside the box.
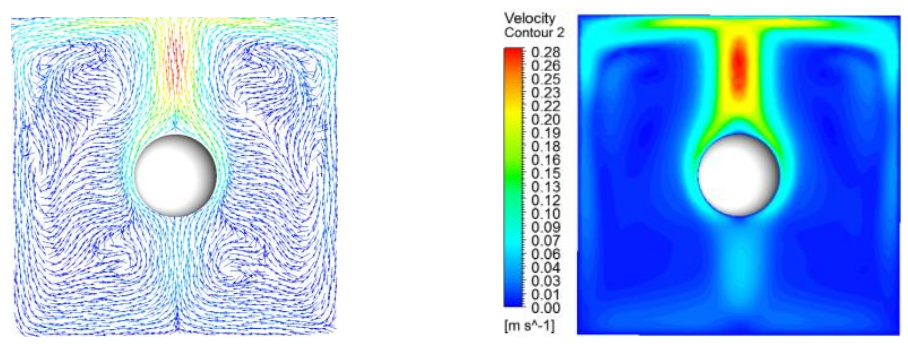

Fig. 7: Velocity vectors and distribution. 
Temperature distribution inside the box is shown on a section plane in (Fig. 8) and it is thought that maximum temperature on top of the box is caused by the rise of hot air.

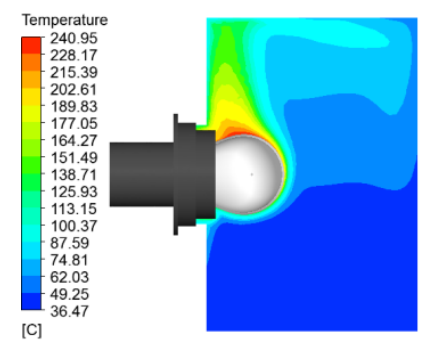

Fig. 8: Temperature distribution inside the box.

\subsection{Effect of the Geometry}

In this phase of the study effect of geometry on temperature over the components is investigated with the help of numerical simulation by varying the distances between the bulb and the lens and the housing.

In the numerical simulation the modelled box consists of housing and a lens to represent an automotive lighting product. The housing is defined as opaque PC/ABS material. Outer surfaces of the housing are considered as black which has the emissivity of $\varepsilon=0.93$ and inner surfaces are thought to be metallized to represent the reflective property of a reflector and emissivity of $\varepsilon=0.15$ is assigned. Lens material is considered as semi-transparent PC. 3D geometry of the housing and lens can be seen below (Fig. 9).

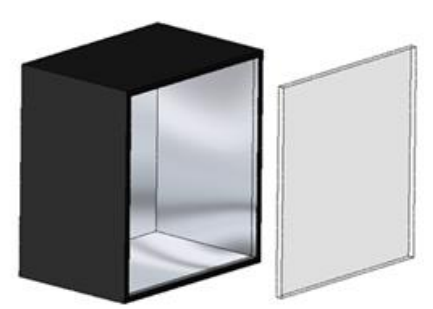

Fig. 9: Geometry used in the simulations.

Schematic representation of the geometry is given in (Fig. 10). z1 in the figure represents the distance between housing top surface and the bulb filament and $\mathrm{y} 1=\mathrm{y} 2$ distances between the side surfaces and the bulb filament and $\mathrm{x}$ is the filament to lens distance.
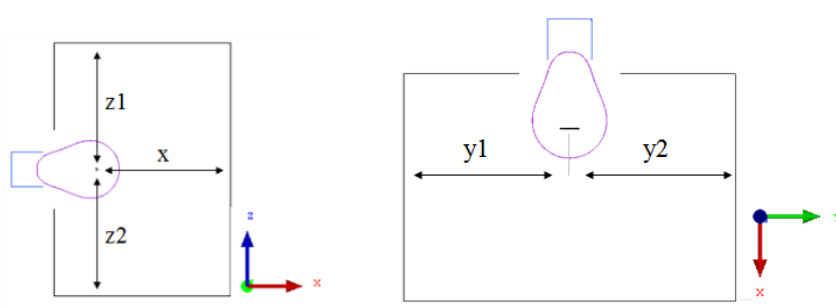

Fig. 10: Schematic representation of the geometry.

\section{Housing Top Surface}

In the first calculation the filament to housing top surface distance is taken as $\mathrm{z} 1=52.25 \mathrm{~mm}$. Simulations are done by increasing the distance by $10,20,30,50,75$ and $100 \mathrm{~mm}$ with constant $\mathrm{x}=52 \mathrm{~mm}, \mathrm{y} 1=\mathrm{y} 2=53 \mathrm{~mm}$ and $\mathrm{z} 2=52.25 \mathrm{~mm}$ dimensions. Maximum temperature is calculated as $103^{\circ} \mathrm{C}$ on housing top surface and $70^{\circ} \mathrm{C}$ on the lens when the $\mathrm{z} 1=52.25 \mathrm{~mm}$. With the increase in $\mathrm{z} 1$ only by $50 \mathrm{~mm}$ and $100 \mathrm{~mm}$ temperatures calculated on housing and lens are $73^{\circ} \mathrm{C}$ and $68^{\circ} \mathrm{C}$ respectively. (Fig. 11) is the graph of the change in maximum housing top surface temperature with $\mathrm{z} 1$ dimension and (Fig. 12) is the temperature distributions on housing top surface of different $\mathrm{z} 1$ dimensions. 


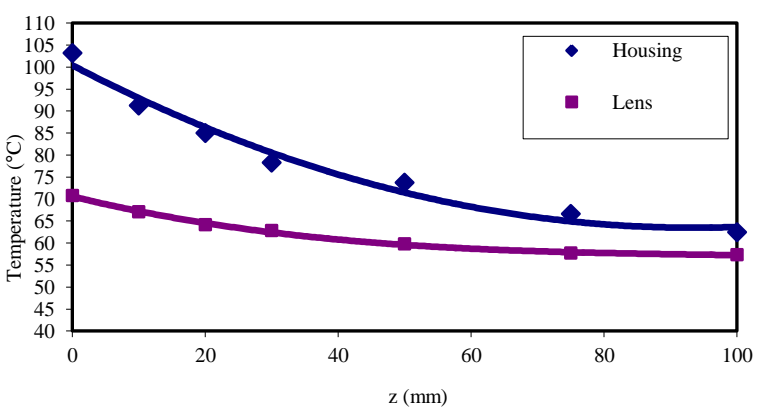

Fig. 11: Change of temperature with $\mathrm{z}$.

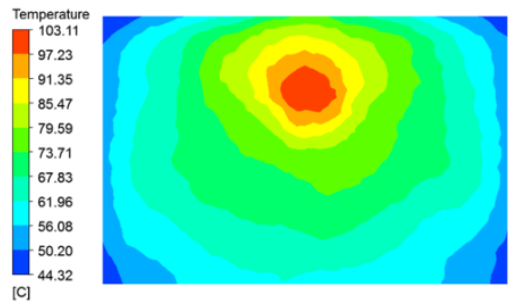

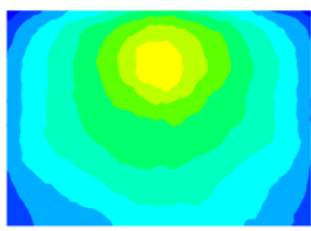

$10 \mathrm{~mm}$

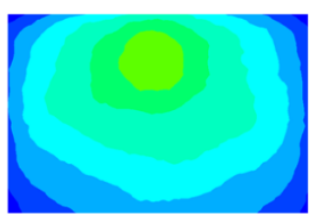

$30 \mathrm{~mm}$

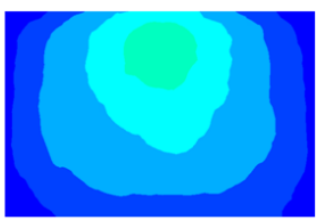

$75 \mathrm{~mm}$

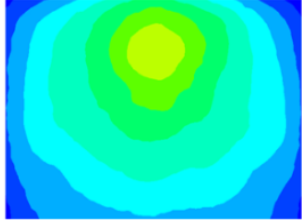

$20 \mathrm{~mm}$

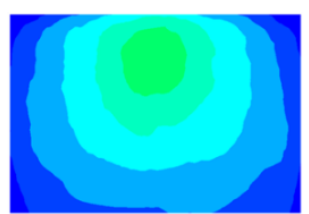

$50 \mathrm{~mm}$

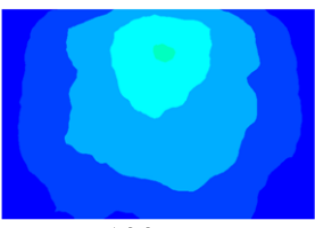

$100 \mathrm{~mm}$

Fig. 12: Temperature distribution on top surface of housing with different $z$.

\section{Housing Side Surfaces}

y1 and y2 dimensions give the filament to housing side surfaces distances. Simulations are done by changing y1 and y2 distances equally and rest of the distances are kept constant. In the first calculation the value of $y 1=y 2=53 \mathrm{~mm}$ is used. By considering $\mathrm{y} 1+\mathrm{y} 2=\mathrm{y}$ and increasing the y by $50 \mathrm{~mm}$ gives the maximum temperature of $91^{\circ} \mathrm{C}$ on the housing. And the lens temperature drops by $8^{\circ} \mathrm{C}$ with this configuration. Taking into account that the y dimension has the least importance compared to other dimensions simulations with different y distances is limited up to $50 \mathrm{~mm}$. Housing and lens temperature change according to y dimension is given in (Fig. 13). 


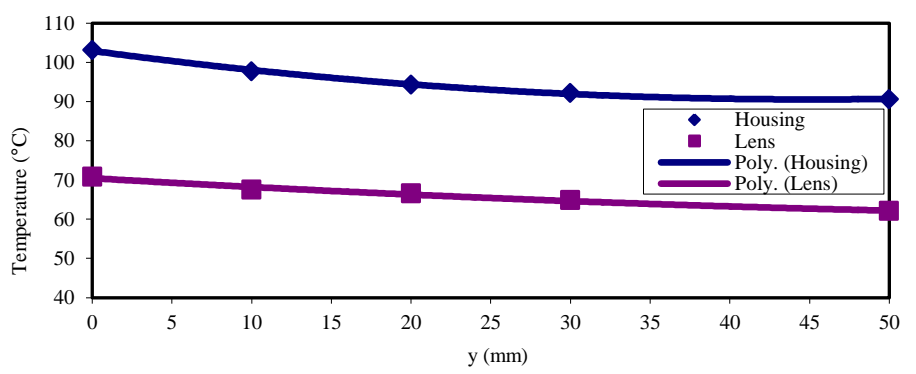

Fig. 12: Change of temperature with y.

\section{Lens Surface}

The dimension $\mathrm{x}$ which is the filament to lens distance is $52 \mathrm{~mm}$ in the first analysis and increased by $10,20,30,50$, $75,100 \mathrm{~mm}$ and maximum temperatures calculated with these distances given in (Fig. 13). According to results with the $100 \mathrm{~mm}$ of increase in $\mathrm{x}$ housing temperature drops by $14^{\circ} \mathrm{C}$ and lens temperature decreases by $16^{\circ} \mathrm{C}$.

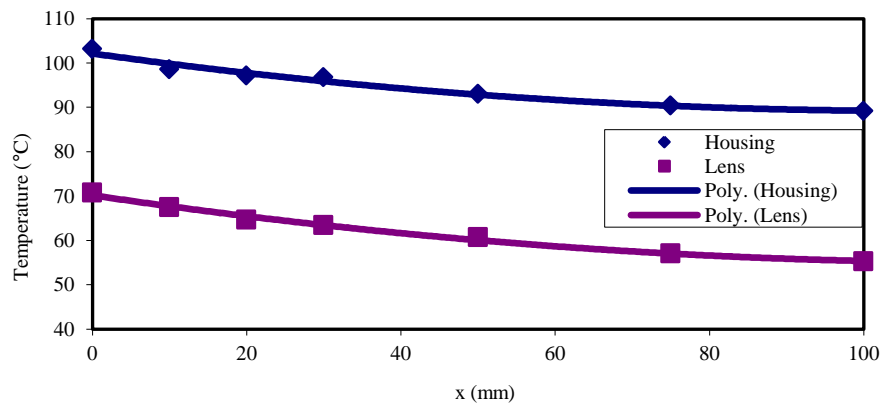

Fig. 13: Change of temperature with $\mathrm{x}$.

\section{Conclusion}

In this study, effect of distances between the light source and surrounding components on temperature is investigated. The numerical study is compared with an experiment. It is seen that temperatures obtained from simulation is consistent with the experimental study.

There has been $40^{\circ} \mathrm{C}$ of temperature drop on housing and $13.5^{\circ} \mathrm{C}$ decrease on lens with the increase of $\mathrm{z} 1 \mathrm{by} 100 \mathrm{~mm}$. It is seen that after a certain z1 value temperature drop on components was reduced. The temperature drop of up to $50 \mathrm{~mm}$ is $30^{\circ} \mathrm{C}$, while the decrease between $75 \mathrm{~mm}$ and $100 \mathrm{~mm}$ is only $4^{\circ} \mathrm{C}$. It is estimated that the effect of the side surfaces is relatively small. The temperature on the housing is decreased by $12^{\circ} \mathrm{C}$ and the lens temperature decreased by $8^{\circ} \mathrm{C}$. The highest decrease in lens temperature was found to be due to $\mathrm{x}$ change. With a $100 \mathrm{~mm}$ increase of $\mathrm{x}$, the lens temperature decreased by $15.5^{\circ} \mathrm{C}$ and this value was found to be close to the value obtained at $\mathrm{zl}$.

It is seen that the largest effect on the body temperature is the distance $\mathrm{z} 1$ and the lowest effect is the distance $\mathrm{y}$ between the study and the parameters examined by increasing the distances in the different directions.

\section{References}

[1] C. Chenevier, "Thermal Simulation in Lighting Systems - 5days/5degrees," Proceedings of the Fourth International Symposium Progress in Automotive Lighting, Darmstadt, Germany, pp. 109-118, 2001.

[2] J. Wulf and A. Reich. "Temperature Loads in Headlamps," SAE Paper, no. 2002-01-0912.

[3] J. M. M. Sousa, J. Vogado, M. Costa, H. Bensler, C. Freek, D. Heath. "An Experimental Investigation of Fluid Flow and Wall Temperature Distributions in an Automotive Headlight," International Journal of Heat and Fluid Flow, vol. 26, pp. 709-721, 2005.

[4] P. Fischer, "Radiative Heat Redistribution and Natural Convection Flow Inside an Automotive Fog Lamp," Proceedings of the Sixth International Symposium on Automotive Lighting, Darmstadt, Germany, 2005. 